\title{
LENGUA Y ESTILO EN CÁNTICO DE JORGE GUILLÉN
}

Victoria G. ReboIRo

Profesora del IES A Cañiza (Pontevedra)

El presente trabajo es un intento de aproximación al estilo de Jorge Guillén. La poesía de Jorge Guillén ha sido definida como una poesía esencialista, epifánica ${ }^{1}$. En efecto, veremos cómo Guillén utiliza una serie de técnicas encaminadas a expresar su asombro ante el mundo (real, concreto) que le circunda.

Para la elaboración del trabajo se ha hecho una lista completa de todas las palabras aparecidas en la antología de Cántico realizada por Philip W. Silver ${ }^{2}$, señalando la cantidad y frecuencia de aparición de cada una de ellas, y se ha estudiado el vocabulario de acuerdo con su significado. Después se han separado las distintas categorías morfosintácticas, y dentro de cada una de ellas se ha establecido una clasificación.

Tras esta clasificación se han estudiado ciertas estructuras sintácticas de aparición recurrente, y algunos artificios de repetición.

1 Vid. Dámaso Alonso, «Los impulsos elementales en la poesía de Jorge Guillén», 1951, en Poetas españoles contemporáneos, Gredos, Madrid, 1965, pp. 201-231. 1982.

2 Jorge Gullén, Mientras el aire es nuestro, edición de Philip W. Silver, Cátedra, Madrid, 


\section{El Vocabulario EN «CÁNTICO»}

Aproximadamente un 55\% de las palabras nocionales recogidas en la versión de Cántico utilizada en el trabajo se refieren a hechos u objetos comprobables a través de los sentidos, es decir, son concretas. El $45 \%$ restante se refiere a ideas o sentimientos, y por tanto se las puede considerar abstractas. Entre las concretas, la mayor parte se refieren a elementos de la naturaleza.

Entre las palabras que hacen referencia a la naturaleza hay tres campos semánticos importantes por su frecuencia. El grupo más numeroso lo forman las palabras relacionadas con la luz; de hecho, la palabra «luz» es el sustantivo que más veces se repite: un total de setenta y una. Los otros dos grupos son las palabras relacionadas con el aire, y las relacionadas con el agua, que son muy numerosas, aunque de repetición menos frecuente.

También dentro del grupo de palabras relacionadas con la naturaleza están las relativas a animales, plantas y árboles, el firmamento, la materia, o partes del cuerpo.

Además de esta mayoría de palabras referentes a la naturaleza, hay algunos grupos menos numerosos pero significativos también. El grupo más importante los constituyen las palabras que hacen referencia a elementos geométricos o arquitectónicos, seguidos de las relacionadas con el lenguaje.

Por último, hay un grupo de palabras de referencia concreta que adquiere importancia por su relación con otros grupos. Son las relativas al cristal. Aunque el cristal no es un elemento natural, en Cántico aparece en relación con la naturaleza, especialmente con la luz y el aire. Así, vemos que de las quince veces que aparece la palabra «cristal», la mayor parte aparece relacionada con la luz, como superficie centelleante:

Cristal hay que recoge el centelleo / De los rayos finales...

Otras veces la cualidad que se destaca es la transparencia:

Este cristal, a fuer / De fiel, me transparenta / la vida cual si fuera / su ideal a la vez.

En cuanto al vocabulario abstracto, predominan las palabras relativas a sentimientos y estados de ánimo sobre las que se refieren a la inteligencia. 


\section{MORFOSINTAXIS EN «CÁNTICO»}

La selección de poemas de Cántico mencionada más arriba, y que ha sido tomada como base para el presente trabajo, consta de un total de 18.424 palabras. De estas, las palabras gramaticales constituyen un $35 \%$, y el $65 \%$ restante se reparte entre adverbios $(2,7 \%)$, adjetivos $(9,7 \%)$, verbos $(14 \%)$ y sustantivos $(38,5 \%)$. Si tenemos en cuenta que los pronombres personales constituyen un $3,5 \%$ del total, llegamos a la conclusión de que las categorías relacionadas con el sustantivo son muy mayoritarias, sobre las relacionadas con el verbo $(51,7 \%)$, frente a un $16,7 \%$ de verbos y adverbios.

Los sustantivos concretos constituyen el $56 \%$ del número total de sustantivos. El $44 \%$ restante son sustantivos abstractos. Dentro de estos últimos hay un grupo importante de infinitivos sustantivados, que constituye un $\mathbf{0 , 8 5 \%}$. del total de sustantivos.

En cuanto a los verbos, el tiempo más empleado es el presente de indicativo, que representa un $54 \%$ del número total de formas verbales.

El segundo grupo en importancia lo constituyen las formas no personales, con excepción del participio, cuya aparición en tiempos verbales es prácticamente nula (no ocurre lo mismo con el participio en función adjetiva, muy frecuente). El gerundio constituye un $10,2 \%$ del total, y el infinitivo representa un $9,1 \%$.

El resto de los tiempos verbales representados son el futuro $(4,4 \%)$, el pretérito indefinido $(2,2 \%)$ y el imperfecto de indicativo $(1,1 \%)$; el presente $(3,9 \%)$ y el imperfecto de subjuntivo $(0,84 \%)$; el imperativo $(3,75 \%)$, y el condicional $(0,75 \%)$. El porcentaje de tiempos perfectos es prácticamente inapreciable.

La mayor parte de las formas personales son de tercera persona (un $58 \%$ de singular y un $23 \%$ de plural). La primera persona del singular constituye un $14 \%$ de las formas personales, y la segunda del singular un $2,2 \%$. Los porcentajes de primera y segunda personas del plural son de un $0,55 \%$ y un $0,22 \%$ respectivamente.

Los pronombres personales más numerosos san también los de tercera persona, que suponen un 54\% del total; los de primera persona son un 36,3\% y los de segunda un $8,7 \%$. Los pronombres más numerosos son los de acusativo, excepto en la segunda persona del singular, donde el pronombre sujeto aparece un mayor número de veces.

Entre las construcciones sintácticas que más llaman la atención en Jorge Guillén destaca el frecuente uso de oraciones de relativo. Aproximadamente un $15 \%$ de los verbos que aparecen en "Cántico" pertenecen a oraciones de este tipo. 


\section{TÉCNICAS DE REPETICIÓN}

Una de las técnicas más usadas por Jorge Guillén es la de comenzar una oración con la misma palabra con la que había terminado la oración anterior:

«Flota una esplendidez / Febril, profundizada / por vistillas de tejas: / Tejas de turba cálida..»: «Perfecto es el amor: / se extasía en sus límites. / ¿Límites! Y la paz / Va apartando los cuerpos...».

Otras veces la repetición no es inmediata:

«Entre el aire Y la luz / Eres Duro elemento. / ¡Eres! Y tan desnuda...»: «El agua desnuda / Se desnuda más».

Abundan las triadas, bien de palabras: «iMás, más. más!...»; «Una seguridad / se entiende, cunde, manda...»; bien de estructuras más complejas: «En blancura de lienzo, / en mano sobre embozo, / en el tendido cuerpo..".

Se repiten también con frecuencia las exclamaciones. como observa José Manuel Blecua ${ }^{3}$, en largas tiradas sin verbos: «TTú, tú, tú... tú, tú sola!».

De lo visto hasta ahora, podemos concluir lo siguiente:

1. Hay un claro predominio de las formas nominales sobre las verbales. A esto hay que añadir que la mayor parte de los verbos son de percepción, pensamiento y emoción. Estamos, pues, ante una poesía en la que apenas hay acción, y en la que abunda en cambio la referencia.

2. Una gran parte de las formas verbales son formas no personales (gerundio e infinitivo). Las formas de tercera persona son mayoritarias entre las personales. Ahora bien, los sujetos de esos verbos son en su mayoría seres $u$ objetos, a menudo personificados. Por lo tanto, se aprecia

3 José Manuel BlecuA, «Introducción» a Jorge Guillén. Cántico (1936), Labor, Barcelona, 1970. 
una clara voluntad de elisión de la persona, en especial de la persona hablante ${ }^{4}$, en favor del mundo que le rodea.

3. La mayor parte del vocabulario es concreto, lo que incrementa el énfasis sobre el mundo real. Las técnicas de repetición mencionadas más arriba tienden también a enfatizar lo concreto, pues lo que se repite son fundamentalmente sustantivos $y$ adjetivos.

4. Pero la visión del mundo que se nos ofrece no es enteramente objetiva. Las exclamaciones indican su emoción ante lo que percibe, que es la nota fundamental de toda la poesía de Guillén. 1980.

4 Vid. Jaime Gil DE Biedma, El pie de la letra. Ensayos 1955-1979, Crítica, Barcelona, 


\section{BIBLIOGRAFIA}

ALonso, Dámaso: «Los impulsos elementales en la poesía de Jorge Guillén», 1951, en Poetas españoles contemporáneos, Gredos, Madrid, 1965, pp. 201-231.

BLECUA, J.M.: «Introducción» a Jorge Guillén, Cántico (1936), Labor, Barcelona, 1970, en F. Rico (1984).

GIL DE BIEDMA, J.: El pie de la letra. Ensayos 1955-1979, Crftica, Barcelona, 1930, en F. Rico, (1984).

Rico, F.: «Historia y Crítica de la Literatura Española». vol. 7. Epoca Contemporánea: 1914-1939, Crítica, Barcelona, 1984.

SILVER. P.W., ed.: Jorge Guillén, Mientras el aire es nuestro, Cátedra, Madrid, 1982. 